\title{
A Bovine Collagen Type I-Based Biodegradable Matrix as a Carrier for Tissue-Engineered Urothelium
}

\author{
Martin Vaegler ${ }^{1 \#, ~ L i s a ~ D a u m #, ~ S a b i n e ~ M a u r e r ~}{ }^{1}$, Arnulf Stenzl ${ }^{2}$, Silke Busch ${ }^{3}$ and Karl-Dietrich Sievert ${ }^{1,2,4 *}$ \\ ${ }^{1}$ Laboratory of Tissue Engineering, Department of Urology, Eberhard Karls University, Paul-Ehrlich-Str.15, 72076 Tübingen, Germany \\ ${ }^{2}$ Department of Urology, Eberhard-Karls University, Hoppe-Seyler-Str. 3, 72076 Tübingen, Germany \\ ${ }^{3}$ Viscofan Bioengineering, a business unit of Naturin Viscofan $\mathrm{GmbH}$, Badeniastrasse 13, 69469 Weinheim, Germany \\ ${ }^{4}$ Department of Urology and Andrology, SALK Universitätklinikum/Paracelsus Medizinische Privatuniversität (PMU), Müllner Hauptstraße 48, 5020 Salzburg, Austria \\ "contributed equally
}

\begin{abstract}
Engineering of lower urinary tract tissue suitable for reconstructive surgery requires biomaterials as cell carriers, particularly in patients for whom autologous grafts are not available. Matrices should support growth, improve mechanical stability, feature excellent biocompatibility, and fully degrade without signs of scarring at the implantation side. In this study, a new bovine collagen type I-based biodegradable non-cross linked matrix was investigated for its suitability as a carrier for porcine and human urothelial cells in vitro. Initial cell adherence, metabolic activity, and proliferation behaviour of cells isolated from tissue biopsies were analyzed. Constructs were characterized immunohistologically in comparison with matrix-free cell sheets established on plastic surface (=controls). Even for high-density seeding, adherence on collagen cell carrier (CCC) was excellent. Metabolic activity and proliferation of stratifying porcine and human urothelial cells cultured on CCC were comparable to that of controls. Immunofluorescence analysis confirmed epithelial phenotype, cell-cell junction formation and ongoing differentiation of the multilayered urothelium on CCC. This study proved CCC as a suitable carrier for urothelial cells for the future aim for urethral reconstruction.
\end{abstract}

Keywords: Urologic tissue engineering; Bioartificial urothelium; Reconstructive urology; Collagen matrix; Biocompatibility; Biomaterial

\section{Introduction}

Urogenital impairment resulting from congenital diseases, traumatic injuries, inflammation, tumours, or medical intervention requires reconstructive surgery techniques. In patients for whom autologous grafts are not available, suitable tissue equivalents are needed for reconstructive purposes [1]. For this reason, tissue engineering (TE) has become a promising technique in recent years $[2,3]$. Current methods of TE aim to develop biological structures and devices that restore, maintain, or improve functions of different diseased mammalian tissues [4]. The primary two TE objectives in reconstructive urology are to provide the surgeon with a tissueengineered construct using "off-the-shelf" material and reduce the need for a second surgical intervention. The first step in TE techniques for the lower urinary tract include the isolation and the expansion of primary urothelial cells followed by the development of a 3D urothelial differentiated and stratified tissue. Monolayered primary urothelial cell cultures are either induced to differentiate and stratify into matrix-free urothelial tissue or are seeded on biodegradable cell carriers to obtain matrix-stabilized urothelium [5-7].

To be suitable as tissue equivalents, biomaterials should support primary cell attachment and proliferation, be biocompatible, induce tissue regeneration, and rapidly degrade in vivo [8,9]. In addition, it should allow the induction of differentiation and development of typical $3 \mathrm{D}$ stratified urothelial tissue. Synthetic polymers [3,10,11], biological compounds such as heterologous acellular tissue matrices including small intestinal submucosa (SIS) [7,12-14], bladder acellular matrix graft (BAMG) [15-18], and naturally-derived processed materials such as collagen $[19,20]$ have been extensively investigated for their applicability. However, the quest for the ideal substitute is still ongoing.

Collagen is the major extracellular matrix protein in vertebrates ensuring integrity of various tissues and organs. It forms a framework in conjunction with other extracellular molecules. Thus, collagen affects cell attachment, proliferation, migration, differentiation, and survival in vivo. Since their enzyme-based degradation does not produce any toxic degradation products, collagens are considered biocompatible. In view of its chemical and physical properties, which include low solubility, controllable stability, biodegradability, low immunogenicity, and high tensile strength, fibrous collagen appears to be an interesting cell carrier material for tissue engineering purposes. Of the 28 collagens identified to date, fibrillar collagen type $\mathrm{I}$ is the most abundant structural component in arteries, bone, cornea, ligaments, skin, and tendons. It represents $90 \%$ of the collagen in the human body and is an important stress-withstanding protein [2123]. Diverse collagen materials have been investigated as matrices or scaffolds in various fields of TE, including urologic TE $[3,24,25]$.

With the focus on reconstructive surgery of the lower urinary tract in tissue engineered matrix-stabilized urothelium, the aim of this study was to investigate the suitability of a new, highly standardised manufactured, ultrathin bovine collagen type I-based cell carrier (CCC) as a matrix for urothelial cells in vitro. We therefore studied this material with regard to the following characteristics: adherence of porcine and human urothelial cells (PUC and HUC) on the CCC, metabolic activity, proliferation behaviour of 3D-constructed urothelial tissues, and its expression profile of specific urothelial markers.

*Corresponding author: Karl-Dietrich Sievert, MD PhD, FACS, FRCS, Professo of Urology, Uro-oncology, Neurourology, Incontinence and Reconstructive Urology and Chair of Department of Urology and Andrology, SALK Universitätklinikum/ Paracelsus Medizinische Privatuniversität (PMU), Müllner Hauptstraße 48, 5020 Salzburg, Austria, Tel: +43 (0) 662-4482-2950/2951; Fax: +43 (0) 662 4482-2944; Email: k.sievert@salk.at, kd_sievert@hotmail.com

Received March 10, 2015; Accepted April 07, 2015; Published April 09, 2015

Citation: Vaegler M, Daum L, Maurer S, Stenzl A, Busch S, et al. (2015) A Bovine Collagen Type I-Based Biodegradable Matrix as a Carrier for Tissue-Engineered Urothelium. J Stem Cell Res Ther 5: 275. doi:10.4172/2157-7633.1000275

Copyright: (c) 2015 Vaegler M, et al. This is an open-access article distributed under the terms of the Creative Commons Attribution License, which permits unrestricted use, distribution, and reproduction in any medium, provided the original author and source are credited. 


\section{Materials and Methods}

\section{Production of the bovine collagen cell carrier (CCC)}

TheCCCused in this study was provided by Viscofan Bioengineering, a business unit of Naturin Viscofan GmbH, Weinheim, Germany. The raw materials for CCC production were bovine hide splits that meet Regulation ISO 22442-2:2007 requirements (Medical Devices Using Animal Tissues and Their Derivatives in terms of tissue safety and traceability-Part 2: Controls on Sourcing, Collection and Handling). The hide splits were dehaired and split into three layers: grain, central, and flesh split, of which the central split was roughly pre-cut, washed with water, and subsequently decomposed using alkaline $\left(\mathrm{Ca}(\mathrm{OH})_{2} /\right.$ $\mathrm{NaOH}, \mathrm{pH} 13$ for $120 \mathrm{~h}$ at $20^{\circ} \mathrm{C}$ ). After neutralization, the material was washed and mechanically processed to obtain a concentrated collagen gel under temperature control of under $23^{\circ} \mathrm{C}$ and finally diluted to a collagen concentration of $2.0 \%(\mathrm{w} / \mathrm{w})$. The $\mathrm{pH}$ value was adjusted to 2.9 and deaerated. The mixture was subsequently passed through a homogenizer, poured through a slit, and the resulting gel film $(21 \times$ $14.8 \mathrm{~cm}$ ) was fumigated with ammonia gas. The physiological $\mathrm{pH}$ value was increased by washing followed by incubation for $30 \mathrm{~min}$ in a $\mathrm{CO}_{2}$ incubator in cell culture medium ( $\mathrm{pH} 7.3$ by a Sørensen buffer/glycerol mixture). The collagen sheets were then sterilized by gamma irradiation (25 kGy) [26].

\section{Culture of porcine urothelial cells}

Porcine urothelial cells (PUC) were isolated either from bladder biopsies or ureter specimens of minipigs under sterile conditions. Tissue specimens were immediately placed in ice-cold transport medium [27]. Tissues of up to $4 \mathrm{~cm}^{2}$ pieces were transferred into a stripping solution containing Hank's Balanced Salt Solution (HBSS)/1\% EDTA (Biochrom), buffered with $10 \mathrm{mM}$ HEPES (Invitrogen) including 20 $\mathrm{kIU} / \mathrm{ml}$ aprotinin (Bayer AG). After $2 \mathrm{~h}$ of incubation at $37^{\circ} \mathrm{C}$, the urothelium was removed from the stroma by means of gentle scraping. Isolated cells were washed in keratinocyte serum-free medium (KSFM; Invitrogen), supplemented with $50 \mu \mathrm{g} / \mathrm{ml}$ bovine pituitary extract, $5 \mathrm{ng} /$ $\mathrm{ml}$ human recombinant epidermal growth factor (both Invitrogen), $30 \mathrm{ng} / \mathrm{ml}$ cholera toxin (List Biological Laboratories), and $100 \mathrm{U} /$ $\mathrm{ml}$ pencicilin $/ 100 \mu \mathrm{g} / \mathrm{ml}$ streptomycin (Gibco). After centrifugation at $250 \times \mathrm{g}$ for $5 \mathrm{~min}$ cells were seeded into CellBIND culture flasks (Corning), subsequently. Urothelial cultures were maintained at $37^{\circ} \mathrm{C}$ in a humidified atmosphere of $5 \% \mathrm{CO}_{2}$. The culture medium was replaced for the first time after 2 days and thereafter every other day. For further passaging, subconfluent monolayers were washed in Dulbecco's phosphate-buffered saline (DPBS) w/o $\mathrm{Ca}^{2+}$ and $\mathrm{Mg}^{2+}$ (Gibco) and cell layers were detached with $0.25 \%$ Trypsin-EDTA (Gibco) incubating for a maximum of $5 \mathrm{~min}$ at $37^{\circ} \mathrm{C}$. Trypsin inhibition was performed with culture medium supplemented with $10 \%$ FCS. After centrifugation cell pellets were resuspended in culture medium after centrifugation and seeded into CellBIND culture flasks.

For stratification experiments, PUC were seeded in high-density $\left(3-4 \times 10^{5}\right.$ cells $\left./ \mathrm{cm}^{2}\right)$. Confluence was checked 2 days after seeding and if found, differentiation was induced by adding $\mathrm{CaCl}_{2}$ to the culture medium to a final concentration of $1.09 \mathrm{mmol} / \mathrm{l}$.

\section{Culture of human urothelial cells}

Human ureter tissue samples were obtained from adult patients (aged 29-74 years; mean age, 52 years) undergoing open nephrectomy (with approval by the local ethics committee). Excess fat and connective tissue were removed. Isolation and culture were performed according to the PUC protocol, with the following modifications as previously described [28]. In brief: After $3 \mathrm{~h}$ of incubation in stripping solution at $37^{\circ} \mathrm{C}$, the urothelium was removed from the stroma by means of gentle scraping, then centrifuged, resuspended and seeded as described above. For further passaging, subconfluent monolayers were incubated in PBS containing $0.1 \%$ EDTA (Biochrom) for $5-10 \mathrm{~min}$ at $37^{\circ} \mathrm{C}$, followed by exposure to trypsin equivalent TrypLE Express (Invitrogen) for another 1-2 min. The detached cells were resuspended in culture medium and seeded into CellBIND culture flasks.

\section{Loading culture dishes with CCC}

Sterile discs of the CCC (diameter $14 \mathrm{~mm}$ ) were transferred into 24-well microplates and soaked with pre-warmed DPBS with $\mathrm{Ca}^{2+}$ and $\mathrm{Mg}^{2+}$ (Biochrom). The discs were adjusted, buffer was suck-off and CCC was dried overnight in the operating laminar flow. After redrying, the CCC attached firmly to the well bottom (Figure 1). Before cell seeding, the dried CCC was equilibrated for $30 \mathrm{~min}$ in $\mathrm{KSFM}$ at $37^{\circ} \mathrm{C}$ and $5 \%$ $\mathrm{CO}_{2}$.

\section{PKH26 labelling}

Subconfluent urothelial monolayers were detached. The suspended cells were labelled with the red fluorescent cell linker PKH26 according to the manufacturer's protocol (Sigma) and seeded on the CCC. As a control, PKH26-labelled HUC were seeded on a standard plastic surface.

\section{Cell adherence}

The degree of primary cell adherence on standard plastic and on the CCC was indirectly ascertained by counting the nonadherent cells in the supernatant 1 day after initial cell seeding and calculating the percentage of non-adherent cells compared to the total number of initially seeded cells. Therefore, both 6 PUC cultures and 6 HUC cultures seeded in low-density $\left(2.5 \times 10^{4}\right.$ cells/ $\left.\mathrm{cm}^{2}\right)$ and seeded in high-density $\left(3-4 \times 10^{5}\right.$ cells $\left./ \mathrm{cm}^{2}\right)$ conditions were counted.
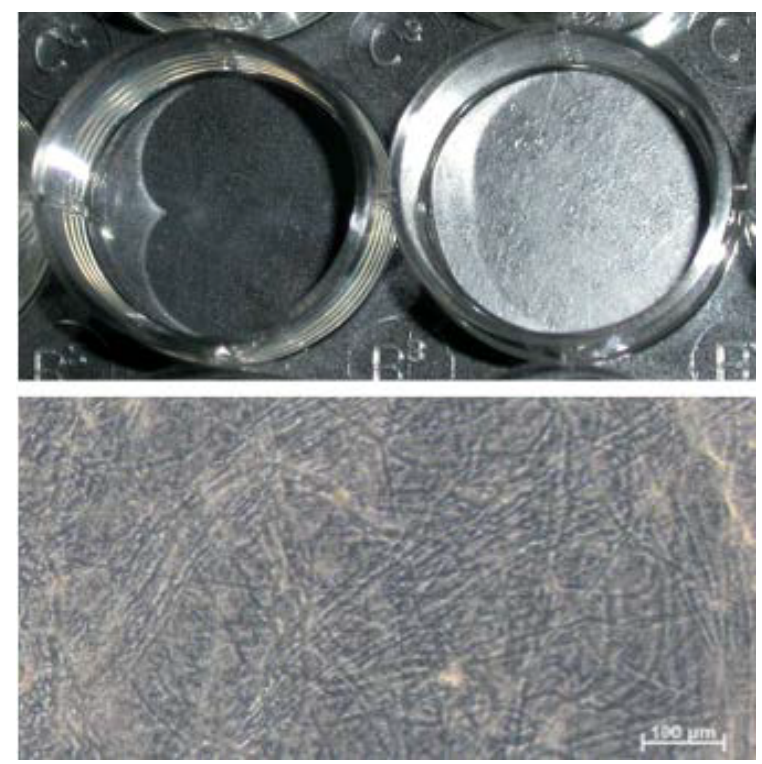

Figure 1: Structural appearance of the collagen cell carrier. (A) Macroscopic top view on two wells of a micro plate coated with (right) and without (left) the matrix. (B) Microscopy phase-contrast view on the matrix with its fiber organization visible. 


\section{Metabolic activity and proliferation behaviour of urothelial cells on the CCC}

The metabolic activity of urothelial cells can be determined relatively via WST-1 assay in viable cells. For quantification of metabolic activity three PUC and HUC primary cultures each were seeded at passages 3-7 with high-density of 3-4 $\times 10^{5}$ cells $/ \mathrm{cm}^{2}$ in 24-well microplates and analysed using WST-1 colorimetric assay (Roche) according to the manufacturer's protocol. The results for CCC were expressed as the optical density (OD) percentage related to the standard plastic surface as control. Analogous to the WST-1 assay, three urothelial cell cultures each (passages 2-7) were seeded and the proliferation behaviour was analysed with the colorimetric 5-bromo-2'-deoxyuridine (BrdU) assay (Roche), according to the manufacturer's protocol.

For both assays experiments were performed each prior to and 1,4 , and 8 days after induction of differentiation.

\section{Immunofluorescence analysis of 3D human urothelium on CCC}

Urothelial cells were seeded in high-density on the CCC, and differentiation was induced in confluent cultures by increasing calcium chloride concentration. On differentiation day 8, multilayered urothelium on CCC were fixed in $3.7 \%$ neutral buffered paraformaldehyde for $10 \mathrm{~min}$ at room temperature, washed with PBS, and embedded in tissue-freezing medium for subsequent cryoconservation. Immunostaining was performed on $5 \mu \mathrm{m}$ cryostat sections with the primary antibodies detecting pankeratin (epithelial phenotype; Millipore), keratin 20 (urothelial differentiation marker; Dako), p63 (epithelial marker; Dianova), zona occludens 1 (tight junctions; Invitrogen) and E-cadherin (epithelial adherens junctions; DAKO). Primary antibody binding was visualized using fluorescein isothiocyanate (FITC)-conjugated polyclonal rabbit-anti-mouse secondary immunoglobulin (Dako). The seeded CCC was compared with matrix-free standard cultures on plastic surface as control.

\section{Results}

\section{Primary cell adherence}

For PUC seeded in high-density on CCC (Figure 2A), the mean percentage of non-adherent cells $(13.6 \%$ of total number of seeded cells) were comparable to controls on standard plastic surface $(12.7 \%)$. In low-density seeding, the mean percentage of non-adherent cells was slightly higher for CCC than for controls ( $15.3 \%$ vs $6.6 \%)$, indicating a decreased initial adherence on CCC.

For adherence of HUC (Figure 2B), the results for high-density seeding were equivalent between standard plastic surface and CCC ( $2.0 \%$ vs. $2.2 \%)$, whereas adherence was decreased for CCC with lowdensity seeding (2.2\% vs. $16.2 \%)$. Note that adherence of HUC was better than of PUC on CCC in high-density seeding (Figures 2A and $2 \mathrm{~B}$, right columns).

\section{Metabolic activity in stratifying PUC and HUC cultures}

Based on the results concerning adherence, the metabolic and proliferation assays were performed only with high-density seeding. For PUC cultures on CCC, metabolic activity determined as mean percentage of control values showed a slightly higher and increasing activity from $104 \%$ at day 0 to $119 \%$ at day 8 after induction of stratification. In stratifying HUC cultures, metabolic activity on CCC remained constant over time at approximately 90\% of control on standard plastic surface (Figure 3).

\section{Proliferation behaviour in stratifying PUC and HUC cultures}

In all the proliferation assays performed prior to induction of

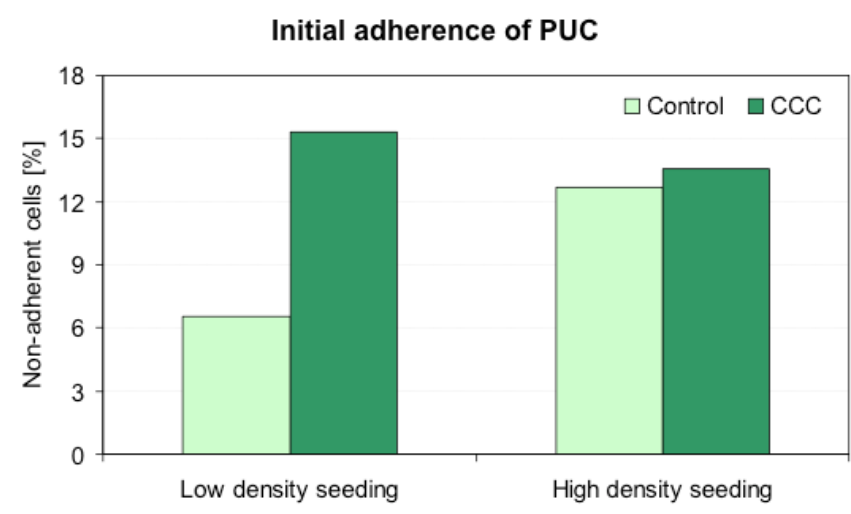

Figure 2: Initial adherence of urothelial cells. (A) The proportion of nonadherent was determined indirectly to total $(A)$ porcine $(n=6)$ or $(B)$ human urothelial cells $(n=6)$ seeded in low- and high-density on CCC compared to those seeded on standard plastic surface as control.

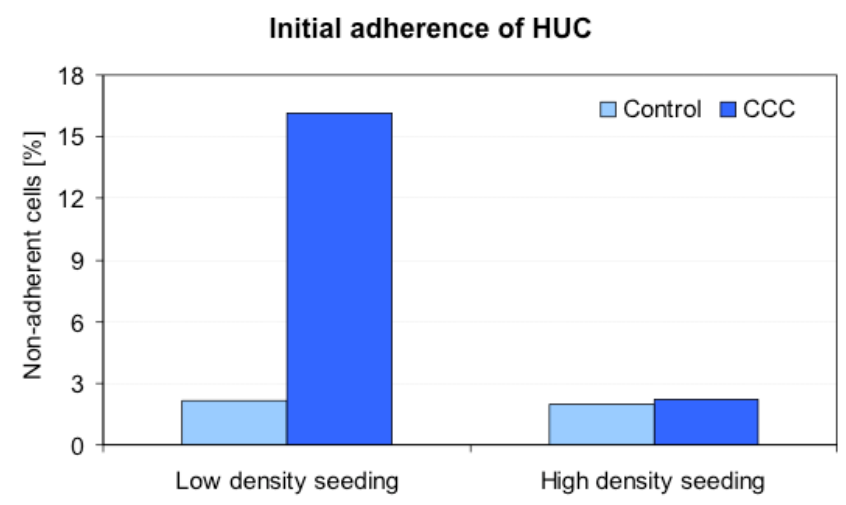

Figure 3: Analysis of metabolic activity via WST-1 assay. HUC and PUC seeded in high-density on CCC were analysed through optical density (OD) measurements regarding their metabolic activity at up to 8 days after induction of stratification. Data is shown as mean percentage of control values for urothelial cells seeded on standard plastic surface $(n=3)$.

WST-1 Assay: HUC vs PUC on CCC

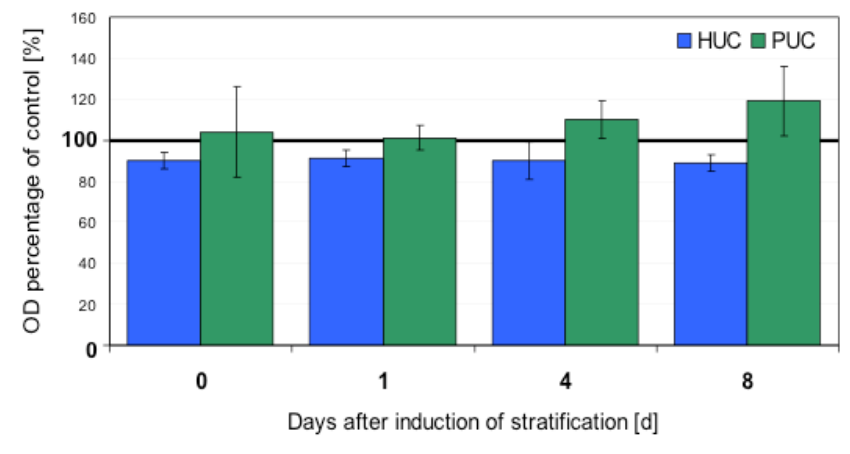

Figure 4: Analysis of proliferation behaviour via BrdU assay. HUC and PUC seeded in high-density on CCC were analysed through optical density (OD) measurements regarding their proliferation behaviour at up to 8 days after induction of stratification. Data is shown as mean percentage of control values for urothelial cells seeded on standard plastic surface $(n=3)$. 
differentiation as well as in the on-going stratification, cell proliferation on CCC was comparable or even exceeded that of the corresponding controls (Figure 4). For PUC, the proliferation behaviour on CCC shown as mean percentages referred to the control values decreased from $122 \%$ to $96 \%$ over 8 days of differentiation. For HUC, a minor drop of proliferation was observed by a mean value trend from $139 \%$ (day 0 ) to $117 \%$ (day 8 ).

\section{Immunofluorescence analysis of 3D urothelium grown on CCC}

Compared to matrix-free established urothelial sheets on standard

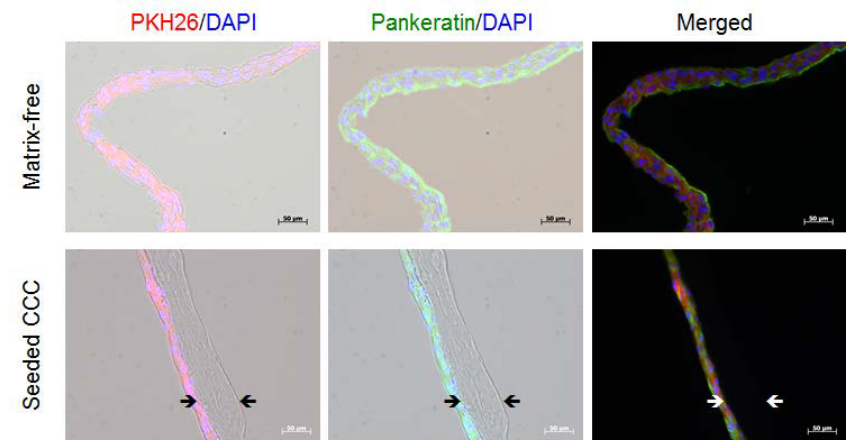

Figure 5: Immunofluorescence analysis of epithelial phenotype. For characterising stratified cultures of $\mathrm{PKH} 26$-labelled $\mathrm{HUC}$ seeded in high-density on CCC the expression of pankeratin, a marker for epithelial phenotype, was determined via immunofluorescence technique. With reference to detached matrix-free controls from standard plastic culture (top row) a comparable homogeneous staining pattern of pankeratin could be detected for in vitro generated urothelium on CCC (bottom row). Red fluorescence for PKH26 and green fluorescence for pankeratin were shown together with blue nucleus signals from DAPI in bright field (left/centre) or as merged (right) photographs.

Matrix-free
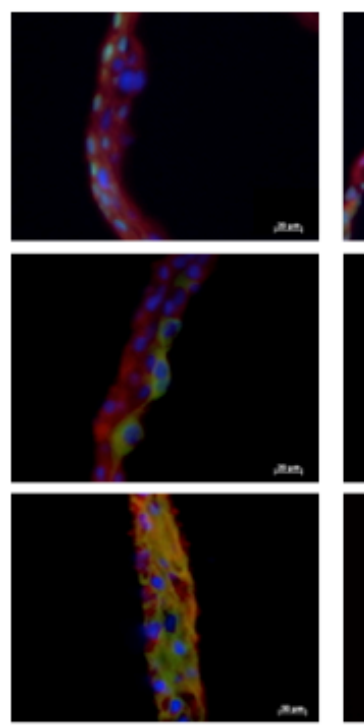

Seeded CCC
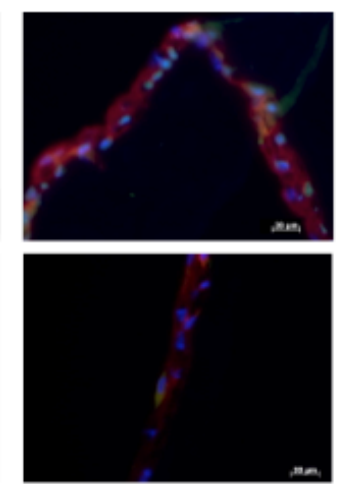

$\mathrm{K}-20$

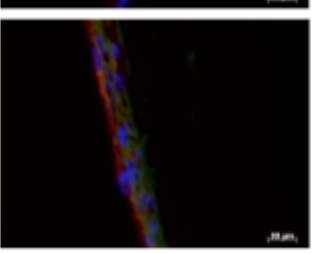

p63

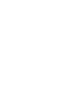

E-Cadherin

Figure 6: Detection of urothelial marker expression. With reference to detached matrix-free controls from standard plastic culture (left column) in vitro generated urothelium of $\mathrm{PKH} 26$-labelled $\mathrm{HUC}$ seeded in high-density on $\mathrm{CCC}$ (right column) showed comparable expression pattern of p63, K-20 (both: ongoing differentiation), E-cadherin and ZO-1 (both: junction formation). Red for PKH26, green for the specific marker and blue signals from DAPI were shown as merged photographs. plastic surface, PKH26-labelled HUC cultures grown on CCC were likewise stained positive for the specific marker pankeratin thus demonstrating an epithelial phenotype (Figure 5). As expected the expression of p63 was most prominent in the basal cell layer. K-20 stained only partially positive, indicating an ongoing urothelial differentiation. Consistent expression of E-cadherin provided evidence for epithelial integrity (Figure 6). Altogether, fluorescence appeared slightly weaker in the flattened cells on CCC than in controls from plastic with more round shaped urothelial cells.

\section{Discussion}

In monolayered urothelial cultures established either from tissue biopsies or from bladder washings, differentiation can be induced by increasing the exogenous calcium concentration after culture confluence has been reached $[29,30]$. Similar to previous studies, we demonstrated that stratified matrix-free urothelial sheets showed immunoreactivity for pankeratin, p63, and partially for K-20 comparable to native human urothelium $[28,30]$. These results indicate the suitability of tissueengineered multi-layered urothelium for applications in reconstructive urology, for example, in urethral reconstruction. Matrix-free cell sheets are fragile, mechanically delicate, and difficult to handle with surgical instruments or even to suture [30,31]. Therefore, different strategies for improving the stability of tissue-engineered urothelial constructs have been pursued. Fraser et al. described the transfer of tissue-engineered, matrix-free urothelial sheets to a polyglactin woven mesh for composite cystoplasty in a minipig model [2]. Although there was no macroscopic sign of shrinkage or contracture, histological analysis revealed that epithelial coverage was incomplete. Another strategy of Shiroyanagi et al. was to autograft in vitro-generated, matrix-free urothelial sheets onto demucosalized gastric flaps resulting in a native-like multilayered epithelium suitable for application in a dog model [32].

A further option is the use of biomaterials as cell carriers to provide mechanical stability and therefore facilitate in vivo application. Additionally, cell carrier matrices can promote urothelial cell growth. The use of poly (lactic-co-glycolic acid) scaffolds for bladder augmentation with or without seeding of cells was investigated by Jayo et al. in a large animal model [33]. Bladder regeneration was more complete with cell-seeded scaffolds than with unseeded scaffolds. These results are consistent with the study by $\mathrm{Fu}$ et al., who also achieved better results with seeded matrices compared to matrix alone used for urethral reconstruction in a rabbit model [34].

Primary cell adherence is the first critical point for the suitability of a biomaterial for seeding specific cell types. Furthermore the proliferation behaviour of the seeded cells is also important. In a previous study, seeding experiments were performed with a commercially available SIS acellular matrix in a serum-free cell culture system [7]. The investigated seeding of HUC on this clinically used matrix showed neither substantial cell adherence, nor measurable cell viability, so that SIS-conditioned cell culture medium was considered to be cytotoxic for HUC. Additionally, porcine DNA residues were detected within the SIS [7].

Biomaterials can be coated with extracellular matrix proteins, other adhesion molecules, or growth factors if necessary to enhance primary cell adherence and cell proliferation. In an attempt to improve primary cell adhesion, Danielsson et al. modified a collagen fleece using a coating with fetal bovine serum proteins and showed that proliferation of seeded smooth muscle cells was improved on these scaffolds and furthermore the released cells could be detected longer in vivo when high cell density seeded collagen fleeces were used for 
transplantation in mice [9]. In a study by Hudson et al., primary HUC attachment was improved on plates coated with collagen type I or IV compared to fibronectin or laminin [35]. HUC grown on fibronectin, collagen type IV, or laminin coating revealed increased DNA synthesis but no differences in metabolic activity were observed between these coatings. Kanematsu et al. incorporated $\beta$-FGF in a collagen sponge and investigated the matrices for functioning as a reservoir of this and others exogenous growth factors when subcutaneously applied in mice. They showed a sustained release and the induction of local angiogenic activity in vivo correlating with the degradation of the matrix [36,37].

In the present experiments, the data concerning primary cell adherence with high-density seeding on CCC were similar to those obtained on standard plastic surfaces, which were interestingly even better for HUC than for PUC. The small decrease that was observed in the initial adherence of both UC cultures with low-density seeding could be a considerable disadvantage in certain experimental settings, but in this instance, it is considered trivial due to the reduced time needed for confluent cell layering where seeding can be executed for a higher amount of cells. Thus, both WST-1 and BrdU assays were also performed after high-density seeding. Together with the subsequent induction of differentiation and stratification, the results showed that HUC seeded on CCC were similarly metabolically active and proliferate well compared to standard cultures. The minor difference in metabolic activity was overcome within the necessary time frame to develop the multi-layered bioartificial urothelium. In contrast to the matrix-free urothelial sheets contracted after detachment from the cell culture dish, the fluorescence of the investigated markers for the controls appeared to be more intense than that for the urothelium-CCC-constructs. Nevertheless, the urothelial phenotype and advanced stratification for both PUC and HUC were confirmed in cell sheets grown on the investigated CCC. Altogether, no indications were found for any cellular toxicity effects being administered through the CCC. This is consistent with the published data of Arana $\mathrm{M}$ et al., who investigated the seeding of ADSC on this kind of CCC matrix successfully and demonstrated the high cell density without any sign of apoptosis.

Collagen is known to induce only minor inflammation and antigenic responses. It combines tensile strength and flexibility and can be processed into different structures [38]. Commercially available collagen matrices show great variation regarding their regeneration potential [26]. They are very thick (e.g. SURGISIS' Soft Tissue Grafts from Cook with $200 \mu \mathrm{m}$ ) which in most cases is associated with the time needed for degradation during in vivo experiments. The investigated bovine collagen type I-based non-cross linked cell carrier, CCC, in this study can be manufactured within a large-scale industrial production process and is of constant high quality. It is characterized by its outstanding biocompatibility; it's very thin film thickness of approximately $20 \mu \mathrm{m}$, its high mechanical stability, its elasticity, and the proven adherence and proliferation of urothelial cells resulting in a wide range of applications in reconstruction of the lower urinary tract. The even better results for HUC-CCC than for the PUC-CCC gives great hope to attain even better results in needed clinical trial.

These characteristics, produced by highly standardised industrial production techniques, offer an interesting biodegradable matrix for use in genitourinary tissue engineering. However, this material has not yet been certified as a medicinal product. Regulatory certification of this particular material is needed to pave the way for clinical application but it is expected to receive approval for the first production line certified by DIN EN ISO 13485 (=medical products) before the end 2015.

\section{Conclusion}

The present study showed excellent adherence of PUC and HUC on the CCC when cells were seeded in high-density without any sign of toxicity for the seeded urothelium cells. The investigations of the metabolic activity and proliferation behaviour even demonstrated good support of urothelial cell growth. The immunohistological analysis of stratifying HUC cultures on CCC revealed homogeneous multilayer formation, ongoing urothelial differentiation, and typical junction formation in vitro. The process of generating a tissue-engineered urothelium was fully capable to manage marginal deviations in the initial culturing. Thus, the data obtained in these experiments demonstrated the suitability of CCC as a collagen matrix for proliferating and differentiating urothelial cells as well as for generating $3 \mathrm{D}$ urothelial tissues in vitro. As the next step towards clinical use of in vitro-generated urothelium-CCC-implants for reconstructive surgery of the lower urinary tract, in vivo investigations will be performed in small and large animal models addressing important aspects of tissue regeneration in urology such as instrumental handling, feasibility, biodegradability, and functional follow-up.

\section{Acknowledgements}

We are grateful to Viscofan Bioengineering, a business unit of Naturin Viscofan $\mathrm{GmbH}$ for providing the collagen cell carriers and for financial support.

\section{References}

1. Atala A (2011) Tissue engineering of human bladder. Br Med Bull 97: 81-104. [PubMed]

2. Fraser M, Thomas DF, Pitt E, Harnden P, Trejdosiewicz LK, et al. (2004) A surgical model of composite cystoplasty with cultured urothelial cells: A controlled study of gross outcome and urothelial phenotype. BJU Int 93: 609616. [PubMed]

3. Atala A, Bauer SB, Soker S, Yoo JJ, Retik AB (2006) Tissue-engineered autologous bladders for patients needing cystoplasty. Lancet 367: 1241-1246. [PubMed]

4. Fuchs JR, Nasseri BA, Vacanti JP (2001) Tissue engineering: A 21st century solution to surgical reconstruction. Ann Thorac Surg 72: 577-591. [PubMed]

5. Maurer S, Feil G, Stenzl A (2005) [in vitro stratified urothelium and its relevance in reconstructive urology]. Urologe A 44: 738-742. [PubMed]

6. Sievert KD, Amend B, Stenzl A (2007) Tissue engineering for the lower urinary tract: A review of a state of the art approach. Eur Urol 52: 1580-1589. [PubMed]

7. Feil G, Christ-Adler M, Maurer S, Corvin S, Rennekampff HO, et al. (2006) Investigations of urothelial cells seeded on commercially available small intestine submucosa. Eur Urol 50: 1330-1337. [PubMed]

8. Alberti C, Tizzani A, Piovano M, Greco A (2004) What's in the pipeline about bladder reconstructive surgery? Some remarks on the state of the art. Int J Artif Organs 27: 737-743. [PubMed]

9. Danielsson C, Ruault S, Basset-Dardare A, Frey P (2006) Modified collagen fleece, a scaffold for transplantation of human bladder smooth muscle cells. Biomaterials 27: 1054-1060. [PubMed]

10. Oberpenning F, Meng J, Yoo JJ, Atala A (1999) De novo reconstitution of a functional mammalian urinary bladder by tissue engineering. Nat Biotechnol 17: 149-155. [PubMed]

11. Raya-Rivera A, Esquiliano DR, Yoo JJ, Lopez-Bayghen E, Soker S, et al. (2011) Tissue-engineered autologous urethras for patients who need reconstruction: An observational study. Lancet 377: 1175-1182. [PubMed]

12. Campodonico F, Benelli R, Michelazzi A, Ognio E, Toncini C, et al. (2004) Bladder cell culture on small intestinal submucosa as bioscaffold: Experimental study on engineered urothelial grafts. Eur Urol 46: 531-537. [PubMed]

13. Ram-Liebig G, Meye A, Hakenberg OW, Haase M, Baretton G, et al. (2004) Induction of proliferation and differentiation of cultured urothelial cells on acellular biomaterials. BJU Int 94: 922-927. [PubMed]

14. Kropp BP, Cheng EY, Lin HK, Zhang Y (2004) Reliable and reproducible 
bladder regeneration using unseeded distal small intestinal submucosa. J Urol 172: 1710-1713. [PubMed]

15. Sievert KD, Tanagho EA(2000) Organ-specific acellular matrix for reconstruction of the urinary tract. World J Urol 18: 19-25. [PubMed]

16. Sievert KD, Bakircioglu ME, Nunes L, Tu R, Dahiya R, et al. (2000) Homologous acellular matrix graft for urethral reconstruction in the rabbit: Histological and functional evaluation. J Urol 163: 1958-1965. [PubMed]

17. Sievert KD, Wefer J, Bakircioglu ME, Nunes L, Dahiya R, et al. (2001) Heterologous acellular matrix graft for reconstruction of the rabbit urethra: Histological and functional evaluation. J Urol 165: 2096-2102. [PubMed]

18. Badylak SF, Freytes DO, Gilbert TW (2009) Extracellular matrix as a biological scaffold material: Structure and function. Acta Biomater 5: 1-13. [PubMed]

19. Nuininga JE, van Moerkerk $H$, Hanssen A, Hulsbergen CA, Oosterwijk-Wakka $\mathrm{J}$, et al. (2003) Rabbit urethra replacement with a defined biomatrix or small intestinal submucosa. Eur Urol 44: 266-271. [Pubmed]

20. Nuininga JE, Koens MJ, Tiemessen DM, Oosterwijk E, Daamen WF, et al. (2010) Urethral reconstruction of critical defects in rabbits using molecularly defined tubular type i collagen biomatrices: Key issues in growth factor addition. Tissue Eng Part A 16: 3319-3328. [PubMed]

21. Patino MG, Neiders ME, Andreana S, Noble B, Cohen RE (2002) Collagen: An overview. Implant Dent 11: 280-285. [PubMed]

22. Yang C, Hillas PJ, Baez JA, Nokelainen M, Balan J, et al. (2004) The application of recombinant human collagen in tissue engineering. BioDrugs 18: 103-119. [PubMed]

23. Cen L, Liu W, Cui L, Zhang W, Cao Y (2008) Collagen tissue engineering: Development of novel biomaterials and applications. Pediatr Res 63: 492-496. [PubMed]

24. Micol LA, Ananta M, Engelhardt EM, Mudera VC, Brown RA, et al. (2011) High-density collagen gel tubes as a matrix for primary human bladder smooth muscle cells. Biomaterials 32: 1543-1548. [PubMed]

25. Montzka K, Laufer T, Becker C, Grosse J, Heidenreich A (2011) Microstructure and cytocompatibility of collagen matrices for urological tissue engineering. BJU Int 107: 1974-1981. [PubMed]

26. Lin HK, Godiwalla SY, Palmer B, Frimberger D, Yang Q, et al. (2013) Understanding roles of porcine small intestinal submucosa in urinary bladder regeneration: Identification of variable regenerative characteristics of small intestinal submucosa. Tissue Eng Part B Rev 20: 73-83. [PubMed]
27. Southgate J, Harnden P, Trejdosiewicz LK (2002) Culture of human urothelium. Wiley-Liss Inc, New York.

28. Feil G, Maurer S, Nagele U, Krug J, Bock C, et al. (2008) Immunoreactivity of p63 in monolayered and in vitro stratified human urothelial cell cultures compared with native urothelial tissue. Eur Urol 53: 1066-1072. [PubMed]

29. Southgate J, Hutton KA, Thomas DF, Trejdosiewicz LK (1994) Normal human urothelial cells in vitro: Proliferation and induction of stratification. Lab Invest 71: 583-594. [PubMed]

30. Nagele U, Maurer S, Feil G, Bock C, Krug J, et al. (2008) In vitro investigations of tissue-engineered multilayered urothelium established from bladder washings. Eur Urol 54: 1414-1422. [PubMed]

31. Sugasi S, Lesbros Y, Bisson I, Zhang YY, Kucera P, et al. (2000) In vitro engineering of human stratified urothelium: Analysis of its morphology and function. J Urol 164: 951-957. [PubMed]

32. Shiroyanagi Y, Yamato M, Yamazaki Y, Toma H, Okano T (2004) Urothelium regeneration using viable cultured urothelial cell sheets grafted on demucosalized gastric flaps. BJU Int 93: 1069-1075. [PubMed]

33. Jayo MJ, Jain D, Wagner BJ, Bertram TA (2008) Early cellular and stroma responses in regeneration versus repair of a mammalian bladder using autologous cell and biodegradable scaffold technologies. J Urol 180: 392-397. [PubMed]

34. Fu Q, Deng CL, Song XF, Xu YM (2008) Long-term study of male rabbit urethral mucosa reconstruction using epidermal cell. Asian J Androl 10: 719722. [PubMed]

35. Hudson AE, Carmean N, Bassuk JA (2007) Extracellular matrix protein coatings for facilitation of urothelial cell attachment. Tissue Eng 13: 2219-2225. [PubMed]

36. Kanematsu A, Marui A, Yamamoto S, Ozeki M, Hirano Y, et al. (2004) Type collagen can function as a reservoir of basic fibroblast growth factor. $\mathrm{J}$ Control Release 99: 281-292. [PubMed]

37. Kanematsu A, Yamamoto S, Ozeki M, Noguchi T, Kanatani I, et al. (2004) Collagenous matrices as release carriers of exogenous growth factors Biomaterials 25: 4513-4520. [PubMed]

38. Kim BS, Baez CE, Atala A (2000) Biomaterials for tissue engineering. World $J$ Urol 18: 2-9. [PubMed] 